\title{
Saphenous vein graft aneurysm nineteen years after aortocoronary bypass surgery: a case report
}

\author{
Miroslav Krpan*, \\ Zoran Miovski \\ University of Zagreb School \\ of Medicine, University Hos- \\ pital Centre Zagreb, Zagreb, \\ Croatia
}

KEYWORDS: saphenous vein graft, aneurysm.

CITATION: Cardiol Croat. 2015;10(9-10):216. | DOI: http://dx.doi.org/10.15836/ccar.2015.216

*ADDRESS FOR CORRESPONDENCE: Miroslav Krpan, Klinički bolnički centar Zagreb, Kišpatićeva 12, HR-10000 Zagreb, Croatia. / Phone: +385-1-2388-888 / E-mail: miroslav.krpan@gmail.com

ORCID: Miroslav Krpan, http://orcid.org/0000-0002-0639-953x •Zoran Miovski, http://orcid.org/0000-0002-3850-8905

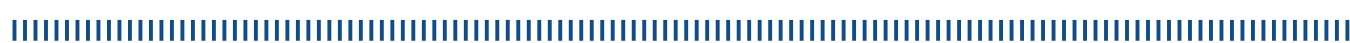

We present a case of a 73-year-old patient who was admitted to our Clinic with complaint of dizziness and fatigue. He denied having any chest pain or shortness of breath. Nineteen years ago he had suffered an inferior myocardial infarction and got surgical myocardial revascularization - aortocoronary bypass surgery with saphenous vein grafts (SVG) on left anterior descending artery (LAD) and right coronary artery (RCA) with no postoperative complications.

During actual hospitalization his ECG showed sinus bradycardia. Chest x-ray revealed nodose infiltrate close to the right side of the heart raising suspicion of intrathoracic tumorous mass. Echocardiography confirmed the presence of paracardial anisoechogenic mass measuring $10 x 7 \mathrm{~cm}$ with partial compression of the right atrium. Color Doppler view of the mass showed pulsatile flow in part of the mass and urgent computerized tomography with intravenous contrast of the thorax and abdomen was performed showing an aneurysm of the SVG on right coronary artery with preserved flow mimicking intrathoracic tumor. Coronary angiogram expectedly showed chronic total occlusion of LAD and RCA and patent SVGs with gigantic aneurysmatic dilatation of the RCA SVG and significant stenosis in proximal part of the LAD SVG.

Currently, patient is pending for surgical resection of the aneurysmatic SVG and myocardial revascularization.

RECEIVED:

July 31, 2015

ACCEPTED:

September 17, 2015

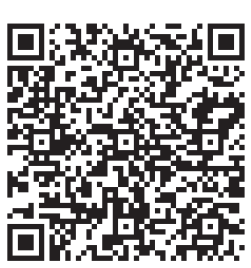

